\title{
Marine and Land Based Arduino Boat
}

\author{
Saloni $^{1}$, Shivangi Kaushal ${ }^{2}$, and Dr. Shalini Bhaskar Bajaj ${ }^{3}$ \\ ${ }^{1}$ Student, Computer Science and Engineering, Amity University Haryana, Gurugram, India \\ ${ }^{2}$ Assistant Professor, Computer Science and Engineering, Amity University Haryana, Gurugram, India \\ ${ }^{3}$ Professor and Head of Department, Computer Science and Engineering, Amity University Haryana, Gurugram, India
}

Correspondence should be addressed to Saloni; singlasaloni004@gmail.com

Copyright ( 2021 Made Saloni et al. This is an open access article distributed under the Creative Commons Attribution License, which permits unrestricted use, distribution, and reproduction in any medium, provided the original work is properly cited.

\begin{abstract}
Disasters are natural calamities which takes place accordingly across the world. Recently, in 2020, various disasters took place which affected the world in various scenarios. During these situations, emergency conditions take place which needs to be handled timely and carefully. So, if any technology contributes to these situations, proves to be a "Boon" for the world. To improve the performance of a vehicle designing is the important aspect for it. At the point when the vehicle runs over a channel at a fast pace, the medium will go along the vehicle in term of obstruction. The reason behind the vehicle going in the opposite direction, when the vehicle moves in at high velocity is because of the structure of the room as there is air space density inside the room. Other than that, the blueprint of the vehicle ought to have an air of fascination with individuals who look at everything about plan as far as inventiveness and aesthetical worth. The land and/or water capable automobile is a double reason vehicle which is described by velocity and intangibility on water, potability, and adaptability ashore and exceptional traffic flow capacity at the intersection of land and water. This project aims to make an Arduino based boat cum car which can highly contribute to disasters. The project would work both as a boat on one side and as a car on other side. These technologies can help people in various ways, for example, rescue operations, essentials delivery, roads having large distance than water and many more. People can use this technology according to the requirement, as a boat or as a car, as and when required.
\end{abstract}

KEYWORDS- Disasters, Arduino Boat, Marine Boat, Rescue Operations,

\section{INTRODUCTION}

Configuration of a vehicle or an automobile is a great angle to be looked over if there is an exhibition of different varieties of them. At the point when the vehicle goes over a medium at rapid, the medium will follow up on the vehicle in term of obstruction [1-4].

Vehicle fuel utilization is big factor which is considered while the vehicle is moving at high pace in the direction opposite to the air as the medium of air will help in the processing. The land and/or water capable vehicle is a double reason vehicle which can be described by quickness and imperceptibility on water, movability, and adaptability ashore and exceptional traffic capacity at the intersection of earth and water [5-8].
It has the highlights of boats yet destroys their cutoff points. This is a direct result of the assets of the land and/or water capable vehicle that numerous operations can be finished without the scaffolds worked by the organization of designers, which incorporates going across the streams, water nets and lakes consistently. Furthermore, it can execute seashore landing, flood help, and watch around, complete the battle duties that vehicles cannot trouble. In the meantime, it shows its tactical worth by the uncommon property of good intangibility, solid attack, just as landing and dispatching under the states of terrible climate and immense wave. D Tank was once designed as the amphibious one in England. The speed can reach $2.4 \mathrm{~km} / \mathrm{h}$ by the path on water [9-13]. The adaptability is the main strategic presentation marker of the land and/or water capable vehicle, choosing the frontline survivability. To accomplish better speed, the adaptability ashore and the speed on water ought to be improved consistently. Along these lines, the developments both ashore and on water have been given expanding consideration [3].

Therefore, 'Amphibious vehicle' is one of the attractive and useful design of vehicles. As the name suggests amphibian means which can travel in water as well on land so the transport vehicles are also named accordingly. It tends to be advanced for the commercialization reason regarding different applications like in the field of military and salvage activities. Specialists are chipping away at land and/or water capable vehicle with capacity to run in unfavorable conditions in productive way. 


\section{LITERATURE REVIEW}

\begin{tabular}{|c|c|c|c|}
\hline Author & Contribution & Method Used & Future \\
\hline $\begin{array}{l}\text { Balasubramanian Esakki, } \\
\text { Surendar Ganesan, Silambarasan } \\
\text { Mathiyazhagan } \\
\text { [1] }\end{array}$ & $\begin{array}{l}\text { Paper discusses design of } \\
\text { Amphibious Vehicle and is } \\
\text { expected to meet disaster } \\
\text { missions }\end{array}$ & $\begin{array}{l}\text { Design of Hovercraft, } \\
\text { Selection of Hull material } \\
\text { and Motors }\end{array}$ & $\begin{array}{l}\text { Need to extend study for } \\
\text { further utilize other } \\
\text { Hardware Components }\end{array}$ \\
\hline $\begin{array}{l}\text { Ihsan, I., Ilham, D. N., Candra, } \\
\text { R. A., Yunan, A., \& Hardisal, } \\
\text { H[3] }\end{array}$ & $\begin{array}{l}\text { Making of Traditional boat } \\
\text { which can turn on and off } \\
\text { the water pump engine }\end{array}$ & $\begin{array}{l}\text { Schema of Boat Drainage } \\
\text { System with Water Pump } \\
\text { Testing }\end{array}$ & $\begin{array}{l}\text { essential need of testing } \\
\text { some more components }\end{array}$ \\
\hline $\begin{array}{l}\text { Prof.Anup } \quad \text { M.Gawande, } \\
\text { Mr.Akshay P. Mali[6] }\end{array}$ & $\begin{array}{l}\text { This paper proposed } \\
\text { amphibious vehicles in } \\
\text { detail and design of } \\
\text { amphibious car }\end{array}$ & $\begin{array}{l}\text { Fabrication and Modelling } \\
\text { of a prototype of } \\
\text { Amphibious car }\end{array}$ & $\begin{array}{l}\text { Quite a simple prototype, } \\
\text { need more design and } \\
\text { modelling }\end{array}$ \\
\hline $\begin{array}{l}\text { S.Renuka , S.Nidish , A.Karan } \\
\text { Raj Selvam[18] }\end{array}$ & $\begin{array}{l}\text { The authors proposed } \\
\text { establishment of technical } \\
\text { aspects of photovoltaic } \\
\text { (PV) system to enhance } \\
\text { power generation }\end{array}$ & $\begin{array}{lrr}\text { Operating } & \text { model } & \text { of } \\
\text { Rectifier } & \text { and } & \text { Boost } \\
\text { Controller } & & \end{array}$ & $\begin{array}{l}\text { Need more study as, the } \\
\text { current urgency requires } \\
\text { an improved model with } \\
\text { high-end performance } \\
\text { accuracy }\end{array}$ \\
\hline
\end{tabular}

\section{METHODOLOGY}

\section{A. About Arduino}

Arduino is an open-source apparatus and programming association, undertaking, and client local area that designs and makes single-board microcontrollers and microcontroller bundles for building automated gadgets and knowledgeable articles with both physical and advanced detecting and control. Its products are licensed under the GNU Lesser General Public License (LGPL) or the GNU General Public License (GPL), allowing anyone to build Arduino boards and distribute software. Arduino boards are commercially available preassembled or as doit-yourself (DIY) kits. It can also accept and send data over the internet with the help of numerous Arduino shields, which are covered in this paper. Arduino employs hardware known as the Arduino development panel as well as software known as the Arduino IDE for code development (Integrated Development Environment) [14$18]$.

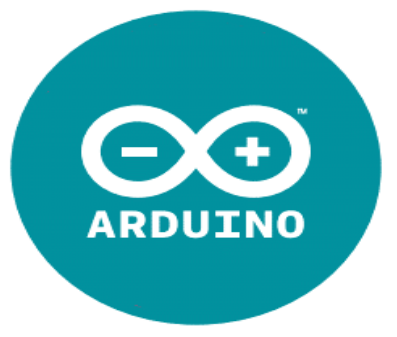

Fig. 1: Arduino IDE

\section{B. $n R F 24 L 01$}

The NRF24L01 [19-22] is a wireless transceiver that uses radio waves to send and receive data. It acts as both receiver and transmitter module with a single chip. It transmits data using the SPI protocol. It has a data transmission rate of up to 2Mbps. The NRF24L01 is commonly used for data transmission in industrial devices and projects. It is mostly used in computer, toys, remote control, games, and other electronic devices.

\section{Features:}

- True single chip GFSK transceiver

- Complete OSI Link Layer in hardware

- Enhanced ShockBurst

- Auto Acknowledgement \& retransmit

- Computation of addresses and Cyclic Redundancy checksum

- On the air data rate 1 or $2 \mathrm{Mbps}$

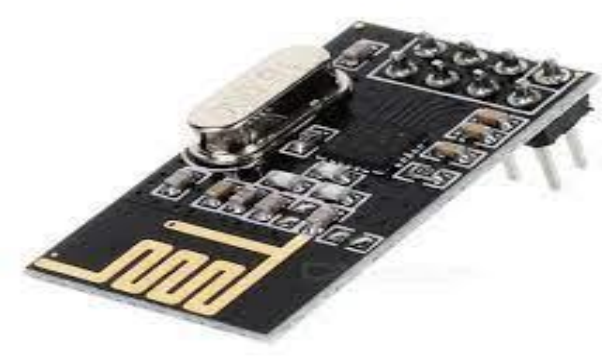

Fig. 2: nRF24L01-Wireless Transceiver

\section{Rain Drop Sensor}

To detect rain there is a tool named Raindrop Sensor. It is basically divided into two different parts: a rain board that detects rain and a control module that evaluates and converts the analog value to a digital form. The rain drop sensor module is an intelligent and low-cost rain sensor. It consists of two sections: a pad that can sense rain and a board to control the device. The sensitive power of the sensing pad perceives any water present on it, whereas the control board orates and binarizes these signals. The rain drop module is widely used in the automotive industry. When rain is detected, it can be used to monitor the weather and send closure requests to shutters or windows. Raindrop sensors are castoff in the automotive industry to automatically control windshield wipers, in agriculture to detect rain, and in home automation systems. 


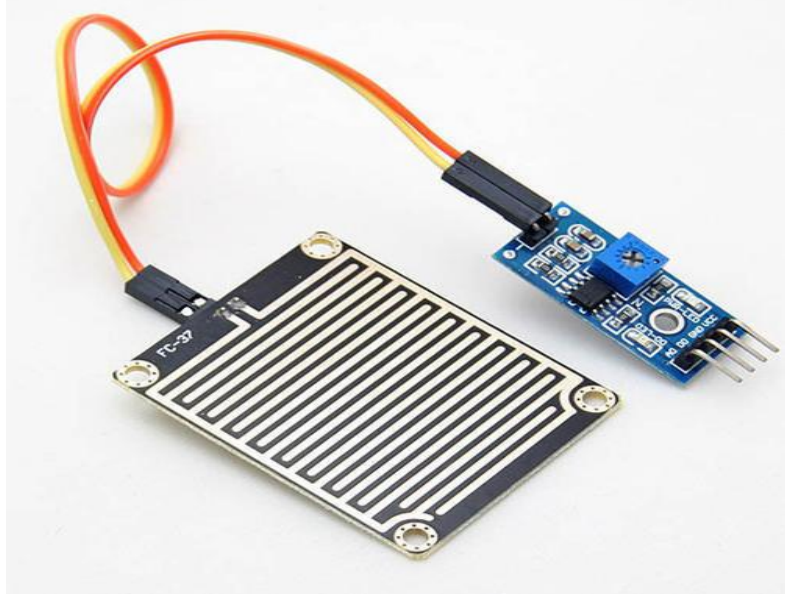

Fig. 3: Rain Drop Sensor

\section{Block Diagram}

Below presented is the block diagram for Marine and Land based Arduino Boat. There exists 4-motors for the car and 2-motors for the boat [23]. A servo motor is there which does the work of switching from car to boat and boat to car respectively. Receiver receives the radio frequency signals and then motor driver control the car.

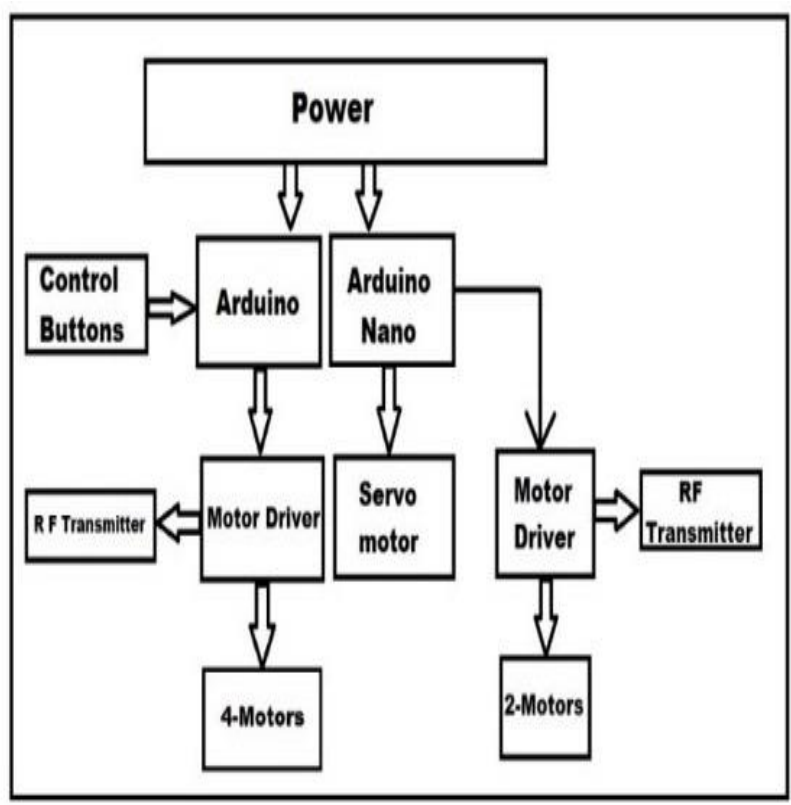

Fig. 4: Block Diagram for Boat

\section{E. Results and Analysis}

Fig 5 shows propellers of boat and rain drop sensor which senses water as soon as water encounters sensor and switches to boat automatically.

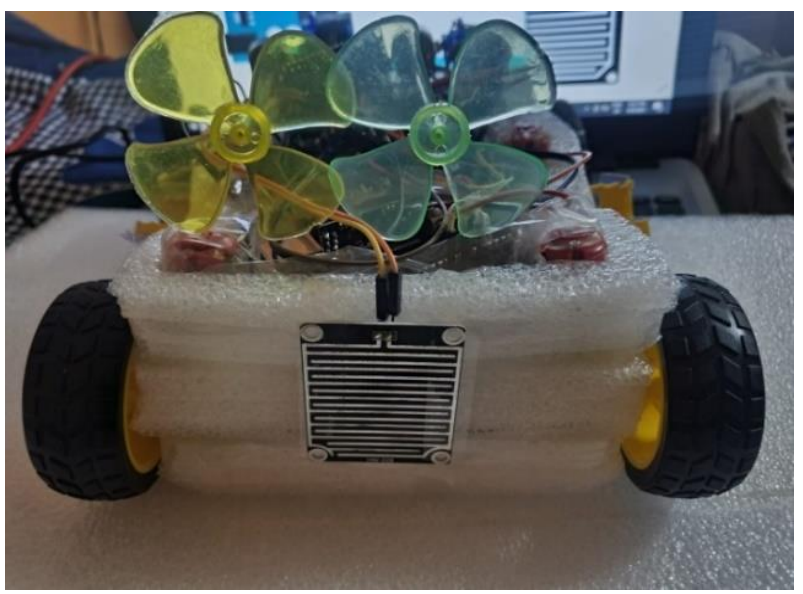

Fig. 5: Working Screenshot-1

Fig. 6 showing propellers started moving the time its rain sensor senses water and switched to boat automatically. In the screenshot it is moving towards left hand side because its right propeller is moving. If it will turn to right, then its left propeller will move automatically.

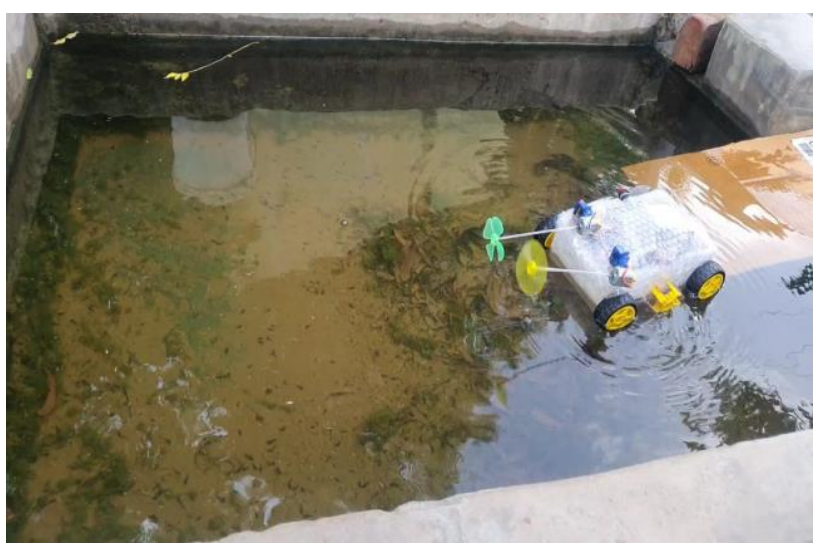

Fig. 6: Working Screenshot-2

Fig. 7 showing boat is changing its direction as it started moving. This is done with the help of joystick which can be operated from a distance. Screenshot showing both the propellers are moving because the boat is moving straight to the water.

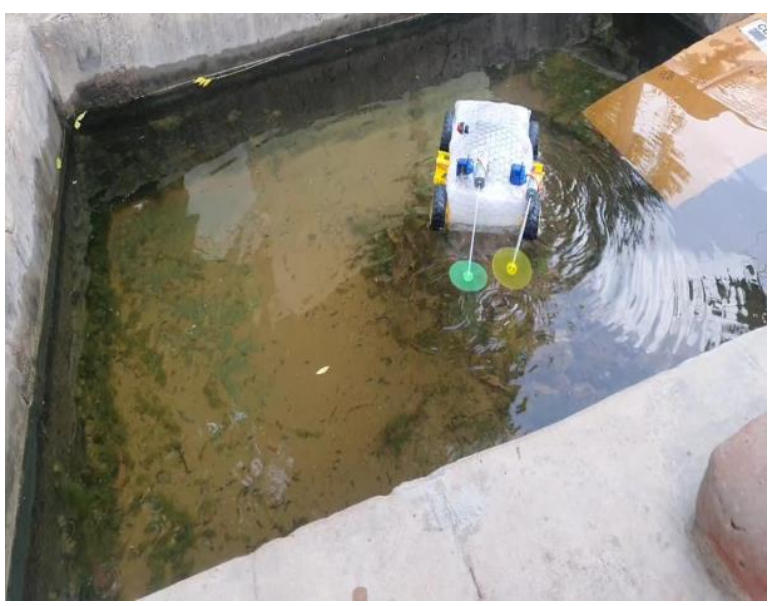


Fig. 7: Working Screenshot-3

\section{CONCLUSION}

Marine and Land based Arduino boat is operable from a distance with the help of a joystick so that it can also work out without human being physically present in vehicle. This can benefit in areas like essentials delivery in remote areas, rescue operations from where people can only sit and come without driving themselves and much more. There are challenges for amphicars but as such there are no disadvantages till now.

\section{CONFLICTS OF INTEREST}

The authors declare that they have no conflicts of interest.

\section{REFERENCES}

[1] Esakki, B., Ganesan, S., Mathiyazhagan, S., Ramasubramanian, K., Gnanasekaran, B., Son, B., ... \& Choi, J. S. (2018). Design of amphibious vehicle for unmanned mission in water quality monitoring using internet of things. Sensors, 18(10), 3318.

[2] ZHAN, C., \& WEI, Q. G. (2018). Numerical calculation of hydrodynamic characteristics of amphibious vehicle during offshore taxiing. Ship Science and Technology, 08.

[3] Ihsan, Ihsan, et al. "Design of an Automatic Water Pump on a Traditional Boat." Sinkron: Jurnal dan Penelitian Teknik Informatika 5.1 (2020): 100-106.

[4] Martinez-Santos, Juan Carlos, Oscar Acevedo-Patino, and Sonia H. Contreras-Ortiz. "Influence of Arduino on the development of advanced microcontrollers courses." IEEE Revista Iberoamericana de Tecnologias del Aprendizaje 12.4 (2017): 208-217.

[5] Al-Ramadhan, A., et al. "The Design of a Boat Safety and Accident Prevention System." 2017 9th IEEE-GCC Conference and Exhibition (GCCCE). IEEE, 2017.

[6] Gawande, M., \& Mali, P. (2016). Amphibious vehicle. International Research Journal of Engineering and Technology (IRJET), 137-138.

[7] Song, Weibo, et al. "The design and application of water jet propulsion boat." 2015 International Conference on Automation, Mechanical Control and Computational Engineering. Atlantis Press, 2015.

[8] LI, C. Y., \& FAN, Z. Y. (2009). Study on Calculation Method of Floating State of an Amphibious Vehicle [J]. Vehicle \& Power Technology, 4.

[9] C.Q. Yang: Theory and Design of amphibious vehicles (Defense Industry Publications, China 2003). (In Chinese)

[10] R.Y. Li: Development and Strategies of Amphibious Tanks (Ordnance and Institute of Informatics, China 1997). (In Chinese)

[11] K. Wu, W. Wang and F. Zhao: Special Purpose Vehicle, Vol. 2 (2004), p.15 (In Chinese)

[12] SONG, G. X., ZHAO, Y. Q., \& WU, K. (2008). 3-D numerical simulation on resistances of amphibious vehicles using two-phase flow. Journal of Harbin Engineering University, 29(9), 907-911.

[13] B.K. Han, X.L. Li and F.C. Sun: Introducing Journal of China Ordnance, Vol. 24 (2003), p.246

[14] J.Y. Wong: Proceeding of the Institution of Mechanical Engineers, Part D, Journal of Automobile Engineering, Vol. 202 (1988), p.143

[15] J.H. Choi, H.C. Lee and A.A: Vehicle System Dynamic, Vol. 29 (1998), p.27

[16] S.V. Balamurugan: Defence Science Journal, Vol. 50 (2000), p. 155
[17] J.H. Lee: A Real-Time simulation model for tracked vehicles (Ph.D., The University of Michigan, America 2006), p.20

[18] Renuka, S., S. Nidish, and A. Karan Raj Selvam. "Electric Boat Using Boost Converter."

[19] Carter A. Malkasian Charting the Pathway to OMFTS: A Historical Assessment of Amphibious Operations From 1941 to the Present CRM D0006297.A2/ Final July 2002.

[20] Savitsky D. and Brown P. W., -Procedures for hydrodynamic evaluation of planning hulls in smooth and rough water", Marine Technology, Vol. 13, No. 4, October, pp.381-400, (1976).

[21] Forbes Aird (1 April 1996) "Fiberglass \& Composite Materials: An Enthusiast's Guide to High Performance Metallic Materials for Automotive Racing and Marine Use", Penguin. pp. 86. Retrieved 12 June 2012.

[22] B. Bhandari design of machine elements (Tata McGrawHill Education 2010).

[23] WU, K., YANG, D. F., \& ZHAO, Y. Q. (2008). The Study on the In and Out Water Character of Amphibious Vehicles. Agricultural Equipment \& Vehicle Engineering, 12.

\section{ABOUT THE AUTHORS}

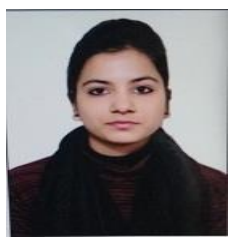

Saloni is pursuing her master's in computer applications from Amity University Haryana. She has undergone course certifications through Udemy. She has interests in Designing and coding.

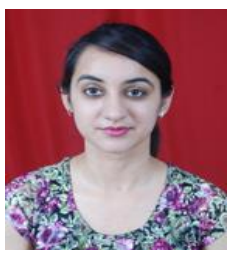

Ms Shivangi Kaushal is currently designated as Assistant Professor in CSE at Amity University Haryana. She has published more than 11 research papers. She is an active Member and Reviewer of several reputed Journals. Her research work includes software testing.

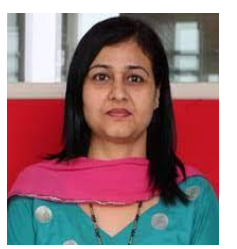

Dr. Shalini Bhaskar Bajaj did her Bachelor of Engineering in Computer Science and Engineering from Deenbandhu Chhotu Ram University, Haryana. After completing her graduation, she worked with Liberty Footwear as System Analyst for a period of six months. Thereafter, she worked as System Analyst in Appware Technologies, LLC, Dubai. Before joining GD Goenka University, she worked with ITM University, Gurgaon. She completed her Master of Engineering in Computer Technology and Applications from Delhi Technological University and Ph.D. from Indian Institute of Technology Delhi (IITD), New Delhi. She has to her credit twenty-two years work experience on different projects, teaching and research in the field of Data mining. She has published more than fifty research papers in different. 